\title{
Dispersive Liquid-Liquid Microextraction and Microsample Injection Flame Atomic Absorption Spectrometry Combination for Copper(II)- 3-hydroxy-4-methyl-2(3H)-thiazolethione Chelates
}

\author{
Zeid A. ALOthman ${ }^{\mathrm{a}}$, Mohamed Habila ${ }^{\mathrm{a}}$, Erkan Yilmaz ${ }^{\mathrm{b}}$, and Mustafa Soylak ${ }^{\mathrm{b} *}$ \\ ${ }^{a}$ Chemistry Department, College of Science, King Saud University, Riyadh-11451, Kingdom of Saudi Arabia \\ ${ }^{b}$ Erciyes University, Faculty of Science, Department of Chemistry, 38039 Kayseri, Turkey
}

\section{INTRODUCTION}

Heavy metals are non-biodegradable and can accumulate in the human body (1). Copper is used in a variety of industrial activities (2) and required as a trace nutrient for plants and animals, but in excess amounts it is toxic (3). High concentrations of copper in the human body may cause stomach and intestinal conditions including vomiting, stomach cramps, and diarrhea. Free copper ions are also highly toxic to marine life. Very high concentrations of copper lead to liver damage and kidney failure. Humans and animals are usually exposed to copper through ingestion of drinking water and foods or through skin contact with copper or copper-containing materials. A copper concentration of more than $1 \mu \mathrm{gL}^{-1}$ can cause a bitter taste in water (4). In lakes, the copper concentrations can range from 0.5 to $1000 \mu \mathrm{g} \mathrm{L}{ }^{-1}$; in groundwater, the average concentration is $5 \mu \mathrm{g} \mathrm{L} \mathrm{L}^{-1}$ (5). Therefore, it is necessary to develop an accurate and sensitive method for the determination of copper concentrations in water and environmental samples (6).

Currently, analytical instruments enable the rapid analysis of environmental samples (7). For instance, spectrometric tools have many applications in the quantification of heavy metal levels in environmental samples. The most commonly used technique is flame atomic absorption spectrometry (FAAS) because it

\footnotetext{
${ }^{*}$ Corresponding author.

E-mail: soylak@erciyes.edu.tr

Fax: +903524374933
}

\section{ABSTRACT}

A novel dispersive liquid-liquid microextraction (DLLME) procedure was developed using 3hydroxy-4-methyl-2(3H)-thiazolethione for the separation and preconcentration of $\mathrm{Cu}$ (II) prior to quantification by flame atomic absorption spectrometry (FAAS). Ethanol $(0.5 \mathrm{~mL})$ was used as the dispersion solvent, and a mixture of ethanol, carbon tetrachloride, and 3-hydroxy-4-methyl-2(3H)thiazolethione was rapidly injected with a syringe into a sample containing $\mathrm{Cu}(\mathrm{II})$. Fine droplets formed, and then the mixture was centrifuged. The lower organic phase was isolated and dissolved in concentrated nitric acid to a total volume of $250 \mu \mathrm{L}$. A $25-\mu \mathrm{L}$ aliquot of this solution was introduced into a FAAS using a microinjection system. The influence of parameters such as $\mathrm{pH}$, volume, and type of the extraction solvent, the volume and type of the dispersion solvent, and the amount of 3hydroxy-4-methyl-2(3H)-thiazolethione was examined. The relative standard deviation (\%RSD), limit of detection (LOD), limit of quantification (LOQ), preconcentration factor (PF), and enhancement factor (EF) were $5.34 \%, 2.54 \mu \mathrm{g} / \mathrm{L}, 8.48 \mu \mathrm{g} / \mathrm{L}, 60$, and 42 , respectively.

The proposed method was evaluated by analyzing certified reference materials and was applied successfully to the analysis of water samples. The presented method can be of particular use to laboratories that do not have access to instrumentation such as graphite furnace, ICP-OES, and ICP-MS. is low cost, easy to use, and has high selectivity. However, under some conditions, FAAS can result in low sensitivity, especially for the analysis of heavy metals in water and some other real samples $(8,9)$. This low sensitivity may be due to the presence of complexes and matrix effects that interfere with instrumental analysis. In addition, some metals are present in the environment at very low concentrations, which may be below the limit of detection of the instrument (10). To perform accurate and sensitive monitoring, separation and preconcentration steps must be performed prior to quantitative analysis. The limit of detection can be improved by separating the species of interest; however, preconcentration simplifies the determination of copper (11).

Recent trends in environmental and analytical chemistry have focused on simplification of the sample preparation steps and use of smaller volumes of solvents and reagents. Many methods are used for this purpose, including liquidliquid extraction (12), solid-phase extraction (13), and cloud point extraction (14). Liquid-liquid extraction (LLE) is an older matrix isolation technique, and dispersive liquid-liquid microextraction (DLLME) has been receiving more interest. The important characteristic of DLLME is the large contact area between the solvent and the aqueous sample, leading to fast separation (15). The advantages of this procedure are ease of operation, speed, low cost, use of low organic solvent volume, high recovery, and 
a high enrichment factor. DLLME has been used for the analysis of organic and inorganic compounds (16-19).

This study aimed to develop a simple, sensitive, and suitable dispersive liquid-liquid microextraction method combined with FAAS for the determination of copper ion concentrations in water samples. The important analytical parameters, including $\mathrm{pH}$, type, and volume of the extraction and dispersion solvents, amount of ligand, sample volume, and the matrix effects, were investigated.

\section{EXPERIMENTAL}

\section{Instrumentation}

The determination of the copper concentrations was performed using a PerkinElmer ${ }^{\circledR}$ flame atomic absorption spectrometer Model 3110 (PerkinElmer, Inc., Shelton, CT, USA), equipped with a hollow cathode lamp for the determination of copper. A Sartorius PT-10 model $\mathrm{pH}$ meter (Germany) was used for the $\mathrm{pH}$ measurements. ALC PK 120 model centrifuges (Buckinghamshire, England) were used for centrifugation of the solutions.

\section{Reagents and Standard Solutions}

All chemicals used throughout this study were of analytical reagent grade. Water purified by reverse osmosis was used. The standard solution of $\mathrm{Cu}$ (II) (1000 $\left.\mathrm{mgL}^{-1}\right)$ was prepared by dissolving the appropriate amount of copper nitrate salt (obtained from Sigma-Aldrich, St. Louis, MO, USA) in $0.1 \mathrm{~mol} \mathrm{~L}^{-1}$ nitric acid $\left(\mathrm{HNO}_{3}\right)$ solution. $\mathrm{NaOH}$ and $\mathrm{HCl}$ were obtained from $\mathrm{E}$. Merck (Darmstadt, Germany). An amount of $0.1 \%(\mathrm{~m} / \mathrm{v})$ 3-hydroxy4-methyl-2(3H)-thiazole-thione (Sigma Aldrich) solution was prepared daily in ethanol. The buffer solutions were prepared according to a method published in the literature (6).

\section{DLLME Procedure}

A sample solution $(20 \mathrm{~mL})$ with a $\mathrm{Cu}(\mathrm{II})$ concentration ranging from 30-50 $\mathrm{g} \mathrm{L} \mathrm{L}^{-1}$ was prepared in a 50-mL centrifuge tube and adjusted to $\mathrm{pH} 2.0$ using a phosphate buffer. To this solution, a mixture of $0.5 \mathrm{~mL}$ of ethanol and $150 \mu \mathrm{L}$ of $\mathrm{CCl}_{4}$, containing $0.05 \mathrm{mg}$ of 3-hydroxy-4methyl-2(3H)-thiazolethione, was rapidly injected using a syringe. The Cu(II) ions reacted with 3hydroxy-4-methyl-2(3H)-thiazolethione, and the solution became cloudy. The mixture was then centrifuged for 5 minutes at $4000 \mathrm{rpm}$, and an aqueous phase and an organic phase were obtained. The aqueous phase was decanted with a pipette. The remaining organic phase, measuring $30 \mu \mathrm{L}$, was brought up to $250 \mu \mathrm{Lw}$ ith concentrated $\mathrm{HNO}_{3}$. A $25-\mu \mathrm{L}$ aliquot of the solution was introduced into the flame atomic absorption spectrometer using a microinjection method (Figure 1) to determine the analyte concentration in the sample solution $(20,21)$.

\section{Analysis of Water Samples}

The certified reference materials (CRM) TMDA-53.3 Fortified Water (National Water Research Institute of Canada, Burlington, ON,
Canada), TMDA-64.2 Fortified Water (National Water Research Institute of Canada, Burlington, ON, Canada), and SPS-WW2 Wastewater (Spectrapure Standards AS, Oslo, Norway) were analyzed using the developed method.

This method was also used to determine the $\mathrm{Cu}$ (II) concentration in tap water, mineral water, dam water, river water, lake water, factory wastewater, mine wastewater, and well water samples. The water samples were filtered through $0.45-\mu \mathrm{m}$ pore size membrane filters immediately after sampling. Then, the procedure described above was applied to all samples.

\section{RESULTS AND DISCUSSION}

\section{Evaluation of Effect of $\mathbf{p H}$}

The separation and preconcentration of heavy metal ions by DLLME is significantly affected by the $\mathrm{pH}$ of the metal ion solution $(22,23)$. The $\mathrm{pH}$ of the medium affects the complex formation between metal ions and ligands and the stability of the resulting complex (24). In the present study, the effects of the $\mathrm{pH}$ of the copper ion solution on the extraction efficiency and the percent recovery were studied in the $\mathrm{pH}$ range of $1-8$.

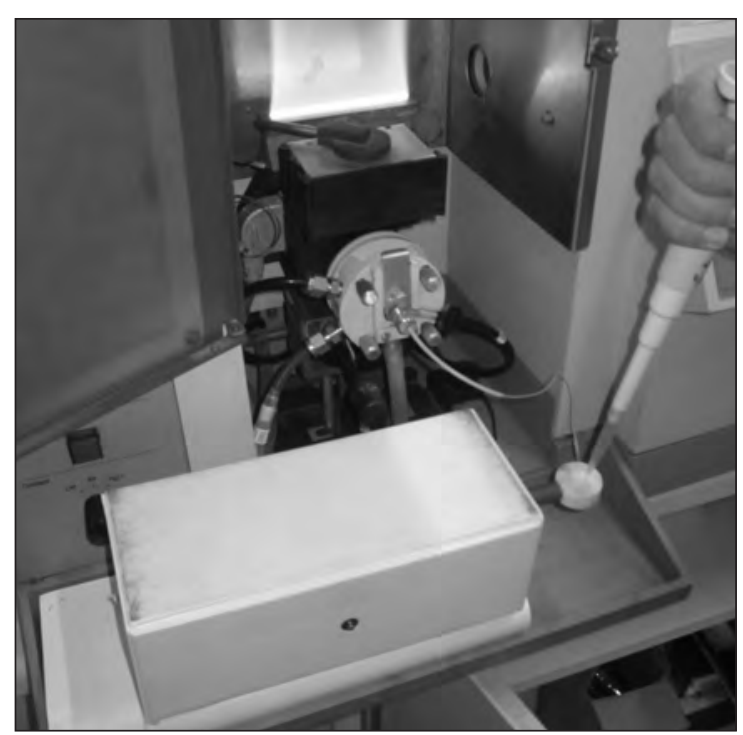

Fig. 1. Photograph of microinjection system for the flame atomic absorption spectrometer. 
As shown in Figure 2, quantitative recoveries were obtained at a $\mathrm{pH}$ between 2 and 4 . A pH of 2 was selected for the subsequent experiments for two reasons. First, a pH of 2 gave the best recovery; second, analyte or matrix precipitation can occur at high $\mathrm{pH}$.

\section{Selection of Extraction Solvent}

The most important factor affecting DLLME is the extraction solvent. Suitable extraction solvents have low volatilities and are able to form cloudy solutions in water. The density of the extraction solvent must be lower than that of water, and extraction solvents with melting points ranging from $10-30{ }^{\circ} \mathrm{C}$ are preferred. In addition, the extraction solvent must have high solubility in the dispersion solvent and low solubility in water $(4,25-27)$.
In this work, five extraction solvents were tested: chloroform $\left(\mathrm{CHCl}_{3}\right)$, carbon tetrachloride $\left(\mathrm{CCl}_{4}\right)$, carbon disulfide $\left(\mathrm{CS}_{2}\right)$, dichloromethane $\left(\mathrm{CH}_{2} \mathrm{Cl}_{2}\right)$, and 1-butyl-3-methylimidazolium hexafluorophosphate (IL); the percent recoveries are shown in Figure 3. It is clear that carbon tetrachloride had the highest percent recovery for the extraction of copper ion, indicating that the most stable cloudy solution was obtained with this solvent.

The volume of carbon tetrachloride was optimized to determine the smallest volume that would still allow quantitative recovery. For this purpose, different volumes of carbon tetrachloride were tested. As shown in Figure 4, maximum recovery (99\%) was obtained with $150 \mu \mathrm{L}$.

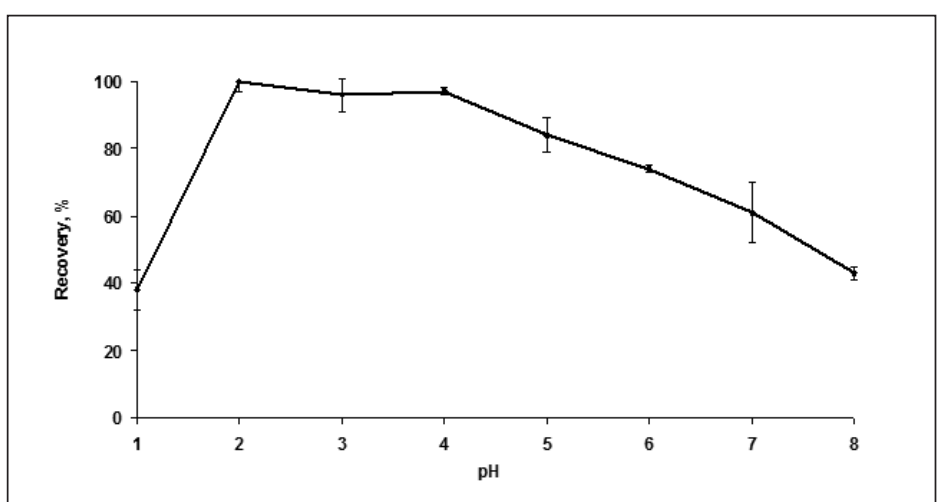

Fig. 2. Influence of $p H$ on the recovery of copper $(N=3)$.

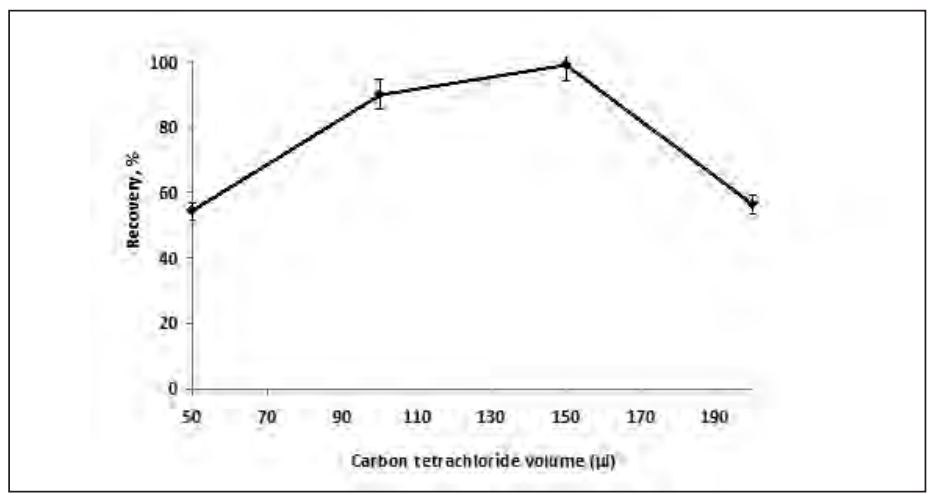

Fig. 4. Effect of volume of carbon tetrachloride on the recovery of copper $(N=3)$.

\section{Atomic Mpectroscopy \\ 1 Vol. 34(5), Sept./Oct. 2013}

\section{Selection of Dispersion Solvent}

The role of the dispersion solvent in DLLME is to act as a bridge that allows the extraction solvent to disperse and form small droplets, making the solution turbid. In turbid solutions, the contact area between the analyte and the extraction solvent is very large, resulting in high extraction efficiency (28). In this study, the effects of five dispersion solvents (methanol, ethanol, propanol, acetonitrile, and acetone) on the \%recovery were evaluated. The results shown in Figure 5 confirm that ethanol was the most suitable dispersion solvent with the greatest possible recovery (100\%). The ethanol volume was also optimized, and a volume of $500 \mu \mathrm{L}$ was sufficient to obtain quantitative results.

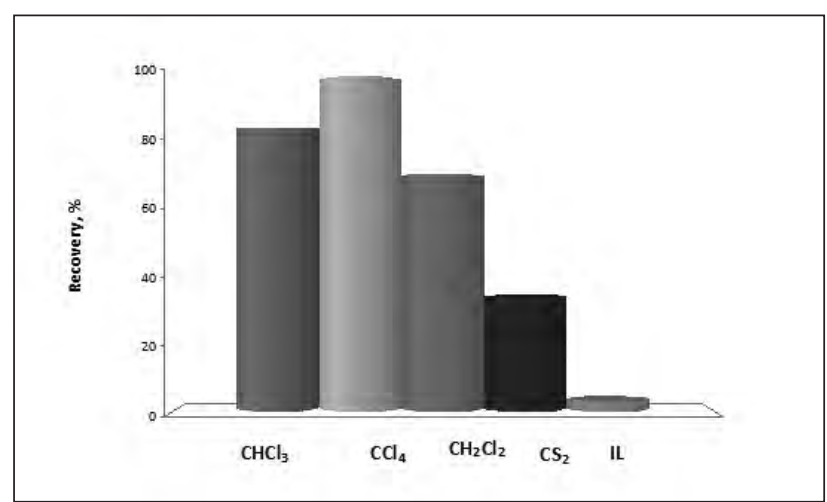

Fig. 3. Effect of type of extraction solvent on the recovery of copper $(N=3)$.

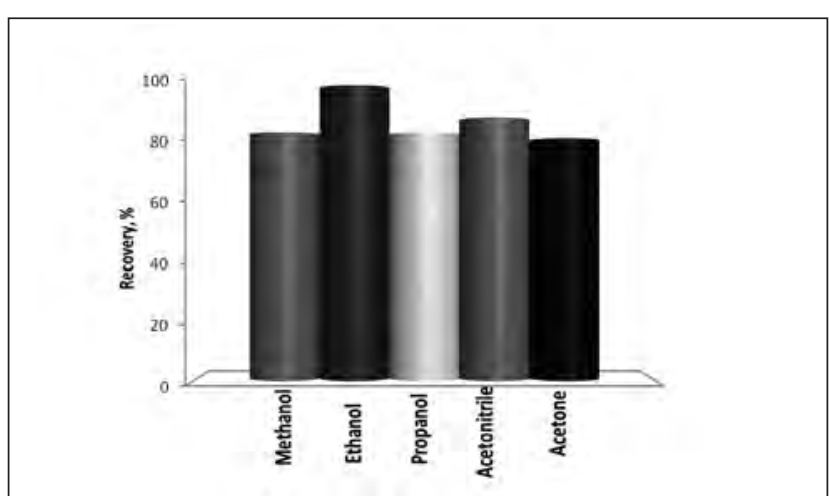

Fig. 5. Effect of type of dispersion solvent on the recovery of copper $(N=3)$. 


\section{Effect of Amount of Chelating Agent}

3-hydroxy-4-methyl-2(3H)-thiazolethione was used to chelate the copper ions in this study. The amount of chelating agent used is a critical factor in preconcentration and separation methods and should be optimized (29-34). The effect of the amount of ligand was tested, and the results are shown in Figure 6. When the ligand was not used, the recovery value was below 5\%. As shown in the figure, best recovery (99\%) was obtained with $50 \mu \mathrm{L}$ of ligand, and this volume was used in subsequent studies.

\section{Interference Studies}

The presence of matrix components or other ions in environmental samples often affects the analytical method (35-42). Therefore, the concentrations of common ions were adjusted individually, and their effects on the recovery of copper were investigated. As shown in Table I, the recoveries were quantitative in the presence of most matrixes tested. These results confirm that the proposed method can be used to analyze real samples with different matrixes.

\section{Influence of Sample Volume}

The ratio between the starting sample volume and the final volume of the extract is a value that determines the preconcentration factor and enables the evaluation of the quality of the proposed method. Therefore, the evaluation of the sample volume is an important step in the preconcentration of copper using DLLME. The effect of sample volume on the extraction of copper was examined for volumes ranging from $10-40 \mathrm{~mL}$.

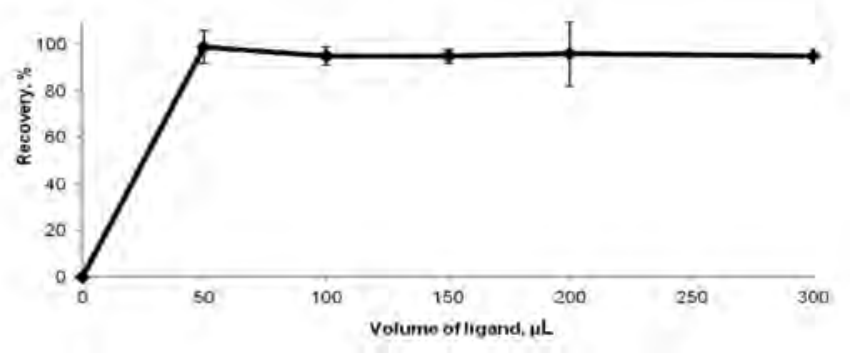

Fig. 6. Effect of amount of 3-bydroxy-4-methyl-2(3H)-thiazolethione on the recovery of copper.

TABLE I

Effect of Matrix Ions on the Recovery of $\mathrm{Cu}$ $(\mathrm{N}=3)$

\begin{tabular}{lcc}
\hline Ions & $\begin{array}{c}\text { Concentration } \\
\left(\mathrm{mg} \mathrm{L}^{-1}\right)\end{array}$ & $\begin{array}{c}\text { Recovery } \\
(\%)\end{array}$ \\
\hline $\mathrm{Na}^{+}$ & 8000 & $99 \pm 5$ \\
$\mathrm{~K}^{+}$ & 5000 & $96 \pm 5$ \\
$\mathrm{Cl}^{-}$ & 5000 & $96 \pm 5$ \\
$\mathrm{Ca}^{+2}$ & 2500 & $106 \pm 8$ \\
$\mathrm{Mg}^{+2}$ & 2500 & $101 \pm 2$ \\
$\mathrm{SO}_{4}^{-2}$ & 2500 & $101 \pm 5$ \\
$\mathrm{PO}_{4}^{-2}$ & 2500 & $100 \pm 3$ \\
$\mathrm{Fe}^{+3}$ & 10 & $98 \pm 4$ \\
$\mathrm{Zn}^{+2}$ & 10 & $104 \pm 2$ \\
\hline
\end{tabular}

Quantitative recovery (>98\%) was obtained for a sample volume of $15 \mathrm{~mL}$. Therefore, $15 \mathrm{~mL}$ was selected as the largest allowed sample volume. The final solution volume was $0.25 \mathrm{~mL}$ and, therefore, the preconcentration factor for copper was 60 .

\section{Accuracy and Application of the Method}

The accuracy of the developed method was demonstrated by the analysis of certified reference materials and by addition-recovery experiments. For this purpose, the developed method was used to analyze three certified reference materials: TMDA-53.3 Fortified Water, TMDA-64.2 Fortified Water, and SPS-WW2 Wastewater. The results of this investigation presented in Table II show that the certified reference materials are in good agreement with the certified values.

Addition-recovery experiments were performed by spiking tap water and mineral water with known amounts of copper to evaluate the DLLME method. For this purpose, known concentrations of $\mathrm{Cu}(\mathrm{II})$ were added to $10 \mathrm{~mL}$ of tap water from Kayseri, Turkey, and to $10 \mathrm{~mL}$ of mineral water sold in a market in Kayseri, Turkey. The recovery values calculated for the added amounts were always higher than $96.6 \%$ (see Table III).

The results obtained for the certified reference materials and the addition-recovery samples indicate that the developed method can be reliably used for the determination

TABLE II Analysis of Certified Reference Materials ( $N=3$ )

\begin{tabular}{lccc}
\hline CRM & $\begin{array}{c}\text { Measured } \\
\text { Conc. } \\
\left(\mu \mathrm{g} \mathrm{L}^{-1}\right)\end{array}$ & $\begin{array}{c}\text { Certified } \\
\text { Value } \\
\left(\mu \mathrm{g} \mathrm{L}^{-1}\right)\end{array}$ & $\begin{array}{c}\text { Recovery } \\
(\%)\end{array}$ \\
\hline TMDA-53.3 Fortified Water & $294 \pm 14$ & 308 & 96 \\
TMDA-64.2 Fortified Water & $266 \pm 16$ & 274 & 97 \\
SPS-WW2 Wastewater & $1940 \pm 80$ & 2000 & 97 \\
\hline
\end{tabular}


TABLE III

Addition and Recovery Studies for Tap and Mineral Water Samples $(\mathrm{N}=3)$

\begin{tabular}{lllc}
\hline & $\begin{array}{c}\text { Spiked Cu(II) } \\
(\mu \mathrm{g})\end{array}$ & $\begin{array}{c}\text { Detected Cu(II) } \\
(\mu \mathrm{g})\end{array}$ & $\begin{array}{c}\text { Recovery } \\
(\%)\end{array}$ \\
\hline Tap Water $(\mathrm{n}=3)$ & 0 & 0 & - \\
& 0.5 & $0.5 \pm 0.12$ & 99 \\
& 1 & $0.97 \pm 0.15$ & 97 \\
\hline Mineral Water $(\mathrm{n}=3)$ & 0 & 0 & - \\
& 0.5 & $0.51 \pm 0.03$ & 102 \\
& 1 & $0.98 \pm 0.18$ & 98 \\
\hline
\end{tabular}

of copper concentrations in water samples. In addition, the developed method was used to determine the $\mathrm{Cu}$ (II) concentrations in water samples from dams, rivers, and lakes, and in samples of factory wastewater, mine wastewater, and well water. The results are given in Table IV.

\section{Characteristics of the Method}

The analysis of the characteristics of this method was performed under optimum conditions using seven measurements of blank and model solutions. The equation of the calibration curve was $\mathrm{A}=0.0211 \mathrm{C}+0.0109$, where $\mathrm{A}$ is the absorbance and $\mathrm{C}$ is the concentration of $\mathrm{Cu}$ (II) in $\mu \mathrm{g} \mathrm{mL} \mathrm{m}^{-1}$. The correlation coefficient was 0.997 . The limit of detection (LOD) and the limit of quantification (LOQ) were $2.54 \mu \mathrm{g} \mathrm{L}^{-1}$ and $8.48 \mu \mathrm{g} \mathrm{L}^{-1}$, respectively (LOD: three times the standard deviation of the blank solution; LOQ: 10 times the standard deviation of the blank solution). The enhancement factor (EF), calculated as the ratio of the slopes of the calibration curves with and without preconcentration, was 42 . The preconcentration factor was 60 [PF: the ratio of the greatest sample volume $(15 \mathrm{~mL})$ to the last volume $(0.25 \mathrm{~mL})]$, and the relative standard deviation (RSD) was $5.34 \%$ for measurements of $50 \mu \mathrm{g} \mathrm{L}^{-1} \mathrm{Cu}(\mathrm{II})$.
TABLE IV

Copper Concentrations in Water Samples $(\mathrm{N}=3)$

\begin{tabular}{lc}
\hline Sample & $\begin{array}{c}\text { Concentration } \\
\left(\mu \mathrm{g} \mathrm{mL}^{-1}\right)\end{array}$ \\
\hline Factory Wastewater & $62.4 \pm 2.5$ \\
River Water & $\mathrm{UDL}$ \\
Dam Water & $\mathrm{UDL}$ \\
Lake Water & $\mathrm{UDL}$ \\
Mine Wastewater & $\mathrm{UDL}$ \\
\hline
\end{tabular}

Mean \pm standard deviation.

UDL: Under the detection limit.

\section{CONCLUSION}

The proposed dispersive liquidliquid microextraction (DLLME) procedure combined with flame atomic absorption spectrometry (FAAS) showed high efficiency for the extraction of low levels of $\mathrm{Cu}(\mathrm{II})$ from water and certified reference material samples and is essentially free from interference. The precision and accuracy of the method are satisfactory. The detection limit and preconcentration factor for copper was found as $2.54 \mu \mathrm{g} \mathrm{L}^{-1}$ and 60 , respectively. The method can be of particular use to laboratories that do not have access to instrumentation such as graphite furnace AAS, ICP-OES, and ICP-MS. The primary advantages of the developed method are the low volume of toxic organic solvent used, low cost, simplicity, high enhancement and preconcentration factors, and short analysis time.

\section{ACKNOWLEDGMENT}

This work was supported by King Saud University, Deanship of Scientific Research, College of Science Research Center.

Received April 29, 2013.

\section{REFERENCES}

1. E.J. Underwood, Trace Elements in Human and Animal Nutrition, Academic Press, New York (1997).

2. M. Soylak, and M. Dogan, Fresen. Environ. Bull. 4, 35 (1995).

3. G.W. van Loon and S.J. Duffy, Environmental Chemistry, A Global Perspective, Oxford University Press Inc., New York (2000), pp. 271-273.

4. M. Soylak, A. Uzun, and L. Elci, Kuwait J. Sci. Eng. 28, 151 (2001).

5. Agency for Toxic Substances and Disease Registry (ATSDR), Toxicological Profile for Copper, Department of Health and Human Service, Public Health Service, GA, USA (2004).

6. M. Soylak and O. Ercan, J. Hazard. Mater. 168, 1527 (2009).

7. A. Tobiasz, S. Walas, B. Trzewik, P. Grzybek, M.M. Zaitz, M. Gawin, and H. Mrowiec, Microchem. J. 93, 87 (2009).

8. F.A. Aydin, and M. Soylak, Talanta 73, 134 (2007).

9. M. Tuzen, M. Soylak, and L. Elci, Anal. Chim. Acta 548, 101 (2005).

10. R. Ansari, T.G. Kazi, M.K. Jamali, M.B. Arain, S.T. Sherazi, N. Jalbani, and H.I. Afridi, J. AOAC Int. 91, 400 (2008).

11. I. Narin, and M. Soylak, Anal Chim. Acta 493, 205 (2003).

12. A. Frankenberger, R.R. Brooks, and M. Hoashi, Anal. Chim. Acta 246, 359 (1991).

13. M. Soylak, I. Narin, L. Elci, and M. Dogan, Trace Elem. Electroly. 16, 131 (1999). 
14. R. Garcia-Sanchez, J. Bettmer, and L. Ebdon, Microchem. J. 76, 161 (2004).

15. F. Pena-Pereira, I. Lavilla, and C. Bendicho, Spectrochim. Acta 64B, 1 (2009).

16. S.Berijani, Y.Assadi, M. Anbia, M.R.M. Hosseini, and E. Aghaee, J. Chromatogr. 1123A, 1 (2006).

17. P. Hashemi, S.M. Hosseini, A. Kakanejadifard, G. Azimi, and S. Zohrehvan, J. Chin. Chem. Soc. 57, 111 (2010).

18. B. Horstkotte, F. Maya, C.M. Duarte, and V. Cerdà, Microchim. Acta 179, 91 (2012).

19. S. Shariati, and M. Golshekan, Acta. Chim. Slov. 58, 311 (2011).

20. H. Berndt, and E. Jackwerth, Spectrochim. Acta 30B, 169 (1975).

21. S.R. Yousefi, and F. Shemirani, Anal. Chim. Acta 669, 25 (2010).

22. H. Zhao, S.Q. Xia, and P.S. Ma, J. Chem. Technol. Biotechnol. 80, 1089 (2005).

23. M. Mirzaei, M. Behzadi, N.M Abadi, and A. Beizaei, J. Hazard. Mater. 186, 1739 (2011).

24. P.O. Oviasogie, and P.O. Okolo, Int. J. Physic. Sci. 3, 56 (2008).

25. M. Soylak, and Y.E. Unsal, Toxicol. Environ. Chem. 94, 1480 (2012).

26. X. Wen, Q. Yang, and Z. Yan, Q. Deng. Microchem. J. 97, 249 (2011).

27. A.N. Anthemidis, and K.I.G. Ioannou, Talanta 79, 86 (2009).

28. A.P. Birjandi, A. Bidari, F. Rezaei, M.R.M. Hosseini, and Y. Assadi, J. Chromatogr. 1193A, 19 (2008).

29. A. Moghimi, J. Chin. Chem. Soc. 55, 369 (2008).

30. M.T. Naseri, P. Hemmatkhah, M.R.M. Hosseini, and Y. Assadi, Anal. Chim. Acta 610, 135 (2008).

31. E. Melek, M. Tuzen, and M. Soylak, Anal. Chim. Acta 578, 213 (2006).

32. M. Soylak, L. Elci, and M. Dogan, J. Trace Microprobe T. 17, 149 (1999).

33. L. Elci, M. Soylak, A. Uzun, E. Buyukpatir, and M. Dogan, Fresen. J. Anal. Chem. 368, 358 (2000).
34. H.B. Senturk, D. Ozdes, A. Gundogdu, C. Duran, and M. Soylak, J. Hazard. Mater. 172, 353 (2009).

35. M. Soylak, and M. Tuzen, J. Hazard. Mater. 138, 195 (2006).

36. I. Ali, Sep. Purif. Rev. 39, 95 (2010).

37. K.O. Saygi, M. Tuzen, M. Soylak, and L. Elci, J. Hazard. Mater. 153, 1009 (2008).

38. T. Akkaya, M. Gülfen, and U. Olgun, React. Funct. Polym. (2013), doi: http://dx.doi.org/10.1016/j.reactfu nctpolym.2013.09.001

39. M. Soylak, and M. Tuzen, J. Hazard. Mater. 152, 656 (2008).

40. Y.L. Yu, Z. Du, and J.H. Wang, J. Anal. Atom. Spectrom. 22, 650 (2007).

41. M. Soylak, and Y. Akkaya, L. Elci, Fresen. Environ. Bull. 8, 453 (1999).

42. S.Z. Mohammadi, D. Afzali, and Y.M. Baghelani, Anal. Chim. Acta 653, 173 (2009). 